\title{
When Is Traditionalism an Asset and When Is It a Liability for Team Innovation? A Two-Study Empirical Examination
}

\begin{abstract}
Team innovation requires idea generating and idea implementing. In two studies, we examine how these two team activities are affected by the extent to which members value traditionalism that is, placing importance on preserving old ways of doing things over breaking precedent and forging new approaches. We proposed that higher average levels of team traditionalism would be negatively associated with idea generating (i.e., given that preserving the old may run contrary to new ideas) but positively associated with idea implementing (i.e., because implementing requires agreement about feasibility of a limited set of ideas and applying them). Conversely, we proposed the exact opposite effects for diversity on team traditionalism (i.e., negatively associated with idea generating and positively associated with idea implementing). Further, we argued that these effects would be mediated by team process conflict because diversity on team traditionalism might make it more likely that members will debate what to retain versus newly adopt; and, team agreement is more likely to occur when team members' values are shared, rather than discrepant, with one another. Supporting our theoretical assertions, we found that whether traditionalism is an asset or liability for team innovation depends on whether: (1) the average level of, or diversity on, team traditionalism is examined; and, (2) idea generating versus idea implementing is of primary importance. Specifically, idea generating benefits the most from higher diversity on team traditionalism, whereas idea implementing benefits the most from higher average levels of team traditionalism. We discuss theoretical and practical implications.
\end{abstract}


International businesses compete for labor, suppliers, distributors, and customers from geographic locations worldwide. These environments make it essential for companies to create teams that can produce innovation, defined as "the intentional introduction and application within a team, of ideas, processes, products, or procedures new to the team, designed to significantly benefit the individual, the team, the organization, or wider society" (West \& Wallace, 1991, p. 303). Approaches to innovation in teams are likely to be shaped by a number of member characteristics, including work experience, functional background, and culture because these factors influence cognitive processes involved in the two components of innovation: idea generating (i.e., coming up with novel and useful ideas) and implementing (i.e., determination of a feasible set of ideas and execution of those ideas for organizational benefit) (DeDreu \& West, 2001). Cultural values constitute a shared meaning system about more versus less appropriate behaviors in a given context (Shweder \& Levine, 1984; Leung, Bhagat, Buchan, Erez, \& Gibson, 2005; 2011) and therefore are likely to influence innovation, which requires determination of not only what is novel but also feasible and appropriate. Despite this, a key limitation of past research on team innovation is that very little has incorporated team members' cultural values, even though there is accumulating evidence that culture and innovative behavior are tightly coupled (Taras, Kirkman, \& Steel, 2010).

Another limitation is that the studies that have examined cultural value effects on team outcomes other than innovation have generally included only a small number of the many potential cultural values that have been identified (see Kirkman, Lowe, \& Gibson, 2017, and Leung et al., 2011, for reviews), most notably individualism-collectivism (i.e., a focus on responsibility to one's self versus groups) and power distance (i.e., acceptance of power differences and hierarchy) (Hofstede, 1980). Even though this research has been helpful in 
understanding the effects of culture on teams, there are likely to be other values besides individualism-collectivism and power distance that are more salient in helping to explain innovation (Gibson, Huang, Kirkman, \& Shapiro, 2014) and hence worthy of investigation. Specifically, a cultural value that is likely to be theoretically linked to innovation in teams is traditionalism, defined as a belief in the maintenance of the status quo, propriety, and restraint of actions or inclinations that might disrupt the social order and traditional norms developed over time within a team or organization (Schwartz, 1990). As the definition suggests, traditionalists place great importance on preserving old ways of doing things over breaking precedent and forging new approaches (Schwartz, 1994). Given the likely effects of traditionalism on the acceptance of novel ideas, as well as attitudes towards, and processes of, change, traditionalism is likely a cultural value of great significance for innovation in teams. This is especially true because when members in a team differ on traditionalism, they are likely to experience process conflict (i.e., "an awareness of controversies about aspects of how task accomplishment will proceed"; Jehn \& Mannix, 2001, p. 239, italics in original). Despite the strong theoretical case to be made for its relationship to innovation, we know of no previous research that has examined the role of traditionalism in teams.

In light of these limitations, our purpose is to investigate the role of traditionalism in team innovation. In doing so, we make three theoretical contributions to the literature on culture and team innovation. First, much of the previous research on cultural values in teams has focused only on average levels of values (see Gibson et al., 2014, for a review). It is only by theorizing about both average levels and diversity on team traditionalism - and their relationship to innovation - that we are able to make predictions about the dual effects on idea generating and implementing in innovation. In so doing, we bridge the cross-cultural psychology and diversity 
literatures to more fully understand the relationship between culture and innovation. We also investigate team process conflict as an underlying theoretical mechanism explaining the relationship between diversity on team traditionalism and idea generating and implementing.

Second, we provide a more fine-grained approach to examining the culture-team innovation relationship by unpacking the two different outcomes that encompass effective innovation: idea generating and idea implementing. By implementing we refer to both determining feasibility of ideas and applying them, consistent with prior research on team innovation (e.g., West, 1990; De Dreu \& West, 2001). Integrating research on traditionalism with the literature on team diversity (i.e., suggesting diverse teams have greater access to skills, abilities, information, and knowledge that positively affect team outcomes; Williams \& O’Reilly, 1998), we argue that the average level of, and diversity on, team traditionalism will affect these two innovative outcomes in opposite ways because creation versus exploitation of new ideas requires different skills and values (Paletz \& Schunn, 2010; Thomas, 1999).

Finally, we provide theoretical insights regarding the uncertainty and liabilities that teams face when trying to discover and exploit opportunities, as documented in the entrepreneurship literature (Stinchcombe, 1965; West, 2002). There is a high failure rate for innovation and research indicates that the causes of failure are most often attributed to issues relating to dynamics between team members (Gorman \& Sahlman, 1989; West, 1990). Providing theoretical richness to the initial formation of these teams, and the types of cultural and mental models that innovators carry into their work, may demonstrate how to mitigate such issues. In doing so, we provide practitioners with advice for enhancing the chances for successful team innovation. Our model is summarized in Figure 1.

Insert Figure 1 about here 


\section{LITERATURE REVIEW}

\section{Prior Approaches to Examining Cultural Values in Teams}

Management scholars have become increasingly interested in the manner in which cultural values influence teamwork (Cramton \& Hinds, 2014; Hajro \& Pudelko, 2016; Taras et al., 2010), particularly in those teams charged with idea generating and implementing (Gibson \& Gibbs 2006). However, much of this research assumes that those with a given nationality will share cultural values, without actually verifying this assumption by measuring beliefs or shared meanings. This comparative research has examined cognition (Gibson \& Zellmer-Bruhn, 2001; 2002), conflict resolution (Zellmer-Bruhn, Maloney, Bhappu, \& Salvador, 2008), leadership (Turetgen, Unsal, \& Erdem, 2008), and trust (Yuki, Maddux, Brewer, \& Takemura, 2005), as well as many other facets of team interaction (see Gibson \& McDaniel, 2010, for a review).

A common approach in this research is to compare teams and their members in one country versus another; however, nation is not the only meaningful group that can and has been studied (Leung et al., 2005; 2011). Within any nation, there is variance in cultural values (Rohner, 1984; Taras et al., 2010; Taras, Steel, \& Kirkman, 2016). However, seldom have scholars examined how this variance affects a team, with several international management reviews arguing that research is sorely needed on how team members manage cultural diversity in ways that increase positive outcomes for individuals and organizations (Gelfand, Erez, \& Aycan, 2007; Kirkman, Shapiro, Lu, \& McGurrin, 2016; Tsui, Nifadkar, \& Ou, 2007).

Recent research has begun to explore diversity in terms of faultlines in teams, which are created when team members' individual attributes (e.g., functional background, gender, age) align and create subgroups (Van der Kamp, Jehn, \& Tjemkes, 2015), with the vast majority of research on faultlines focusing on demographic differences because these are easily 
operationalized as categories that might overlap. For instance, a faultline exists when all the women in the team are engineers and all the men are designers. In contrast, our logic for the effects of cultural value diversity is different, given that values are conceptualized as continuous variables, rather than categories, and given we view cultural value diversity as a type of variety diversity (Harrison and Klein, 2007), in which members exhibit differences in the kind of knowledge, information and experience that they contribute. As Harrison and Klien (2007) reviewed, this type of diversity often has positive implications for teams; for example, it can increase creativity (which is related to idea generation). In contrast, most of the faultline framework is based on the idea that demographic alignments in teams are inherently conflictual (Phillips, Mannix, Neale, \& Gruenfeld, 2004; Sawyer, Houlette, \& Yealey, 2006). Yet empirical studies have reported a variety of effects, including positive ones (e.g., Gibson \& Vermeulen, 2003; Thatcher, Jehn, \& Zanutto, 2003). Likewise, meta-analyses of team diversity more broadly suggest that team type and the type of outcome in focus moderate the effects of diversity in teams (e.g., Joshi \& Roh, 2009; Stahl et al. 2010).Thus, one can reasonably assume that team diversity effects depend upon not only on the particular aspects of team composition in focus and how diversity is operationalized, but also on the specific outcomes of interest.

\section{A Brief Review of Traditionalism}

Traditionalism is a cultural value that is highly salient in generating and implementing of innovative ideas. As noted, those with strong traditionalism values preserve the status quo and, thus, are likely to resist proposing or accepting new ideas that create change (Yang, 2003). Consistent with this, other scholars have noted that those high on traditionalism have great care and concern for the past and, in turn, make attempts to integrate it into the present (Hobsbawm, 1983). The result is that change occurs very slowly (Brett, Tinsley, Shapiro, \& Okumura, 2007). 
The slowness of change-supportive actions among individuals who value traditionalism is due to their belief that if new social conditions impose the need for changes, they need to be rooted in examples from the past, so that social continuity (either imaginary or real) is not interrupted (Hobsbawm, 1983). In contrast, those lower in traditionalism prefer to break precedent, and hence embrace change or place priority on being novel and original (Chang, 2012).

Prior research has consistently found that individuals in regions of the world where Confucianism is prevalent are typically higher on traditionalism (Yang, 2003; Kwan, 2009). From an Eastern perspective, traditionalism is often referred to as a typical pattern of motivational, evaluative, attitudinal, and temperamental traits that is most frequently observed in Chinese-origin societies, such as Taiwan, Hong Kong, Singapore, and mainland China (Yang, 2003). Themes that are commonly associated with traditionalism from Eastern research include: submission to authority, thriftiness, conservatism, endurance, obedience, reliance, and fatalism (Zhang, Zheng, \& Wang, 2003), all values that are also typical of more agrarian societies. However, rather than simply coding nationality and assuming shared values of traditionalism in certain nations versus others, we are careful here to directly assess traditionalism among participants, unlike much prior research, and argue that examining traditionalism in this way can lead to important insights about successful idea generating and idea implementing.

\section{HYPOTHESIS DEVELOPMENT}

\section{The Effects of Average Level of, and Diversity on, Team Traditionalism on Idea Generating and Implementing}

Team innovation requires both developing new ideas and determining which ideas are implementable; that is, reducing ideas to a feasible set, given a specific context, and applying those ideas (Amabile et al., 1996; DeDreu \& West, 2001; Gibson \& Gibbs, 2006). Initially, a 
team's members must recognize opportunities for innovation and develop a broad set of novel paths forward, but eventually this must be reduced to only those that are feasible if execution and stabilization of the innovation are going to occur (West, 1990). Hence, as a team moves into implementing and determines the feasible set, innovation depends critically on team processes, which serve as innovation carriers and ensure that ideas are checked and processed before proceeding to executing (Drach-Zahavy \& Somech, 2001).

In teams, interactions between members with diverse knowledge augments an organization's capacity for making novel linkages and associations beyond what any one individual can achieve, and this necessitates an ability of a team to recognize the value of new information, assimilate it, and apply it to commercial ends (Cohen \& Levinthal, 1990). Team innovation requires not just creative thinking, but also the capacities to recognize, assimilate, and apply these ideas to identify the most feasible ones in a given organizational setting so that later they can be seen to fruition in the form of new products or services (De Dreu \& West, 2001). Indeed, empirical research has revealed that higher minority dissent in teams leads to more creative ideas, but it is only when those novel ideas are implemented through team participation that they become innovative procedures, services, and products (De Dreu \& West, 2001).

Whereas the initial idea generating phase requires seeing new options, alternatives, and possibilities (Kwang \& Rodrigues, 2002; Kirton, 2006), in contrast, identifying implementable ideas requires selling ideas to others in order to move the ideas from abstract concepts to feasible and tangible deliverables (Dutton, Ashford, O'Neill, \& Lawrence, 2001). Selling behaviors often include upward influence tactics aimed at enhancing the perceived value of creative ideas through rational persuasion with a focus on idea feasibility and are often directed at senior leaders in an organization (Yukl \& Falbe, 1990; Yukl, Kim, \& Chavez, 1999). Thus, 
implementing requires articulating a vision, having the capability to solve a problem, or leveraging a new opportunity for improvement; and, ideas will only be deemed feasible if this vision fits with an organization's operational norms and protocols (Dutton \& Ashford, 1993). Rather than seeking to generate more options to consider, when identifying feasible ideas, a team's members must emphasize a reasonable chance of success in a specific context, providing evidence as to how an idea can feasibly further an organization's agenda (Mueller et al., 2011).

We argue that the average level of team traditionalism is likely to have differential effects on idea generating versus idea implementing. ${ }^{1}$ Novelty - the distinguishing characteristic of a creative idea, differentiating it from an idea which is merely useful - connotes that an idea has uncertain future value (Mueller et al., 2011). Relative to proven solutions, individuals know less about whether new processes, ideas, and procedures will generate revenue for organizations, how much they will cost to make, and what resources (e.g., time, materials, skills) are needed to produce them (Klein \& Knight, 2005). When the central tendency in a team is to be high on traditionalism, that team's members are likely to tend toward the status quo, as even if one extreme individual expresses a creative idea, those with the tendency to uphold tradition will have a strong inclination to overrule such ideas. Such an effect can be explained by relative cultural distance (Thomas, 1999), which suggests that an individual member of a team can be culturally different from the prevailing team culture. Such a difference means that even though a team member might have unique ideas, high average levels of traditionalism (i.e., all members are relatively high on traditionalism except for one) are likely to enforce an overall team climate that discourages divergent thinking, which will have a chilling effect on the culturally distant team member.

In addition, there is a tendency in teams for members to introduce and discuss only 
information and ideas that are already known by team members, something that is referred to as the common knowledge effect (Gigone \& Hastie, 1993). The reason the effect occurs is because members are afraid that bringing up unique or unpopular or information or ideas might put them at risk for ostracizing by fellow team members. It is highly likely that the common knowledge effect is even more prominent in teams with high average levels of traditionalism, because there will be a strong team climate, rooted in culture, that views novel ideas with derision.

Conversely, when the central tendency in a team is to be low on traditionalism, there will be an overall team climate that welcomes generating novel ideas and being willing to break with precedent. When team members express novel ideas, fellow team members are likely to respond positively, reinforcing team norms around generating ideas. If there is one member of a team who is culturally distant on traditionalism and thus resists discussing divergent ideas, the lack of participation from that member will not likely overcome the open team climate produced by low average levels of traditionalism. In addition, the common knowledge effect is much less likely to occur in teams with lower, rather than higher, average levels of team traditionalism because such a team's climate will be receptive and encouraging of discussing novel ideas and information.

Supporting our theoretical arguments, empirical research has found that many cultures in which traditionalism is prevalent struggle with developing the creativity necessary for the idea generating component of innovation. For example, in China, Yi et al. (2013) found a general decline in creativity among students from 10 to 16 years of age, which they attributed to a more academic, less creatively supportive environment in the upper grades, due to the pressure associated with college entrance examinations. This has led some scholars to claim that the exam-driven, conventional education in many countries where traditionalism is valued may result in the sacrifice of independent intellectual inquiry and creative thinking (Niu \& Sternberg, 
2001, 2003). Building on our theoretical logic and supportive empirical research, we predict:

\section{Hypothesis 1. The average level of team traditionalism is negatively related to the innovative quality of ideas generated in teams.}

On the contrary, as a team moves into application, this phase requires more critical evaluation of ideas for their practical feasibility and utility and, thereby also, their implementability. This requires that team members understand, respect, and work well within an organizational structure, adhering to norms, rules, and protocols to see their ideas through to fruition. For that subset of ideas that are deemed as feasible, members must then garner resources and support, ensuring they are leveraged and incorporated into existing marketing and production planning or other operations (Knudsen \& Levinthal, 2007). Based on this, we argue that teams with high average levels of team traditionalism will be better suited for idea implementing because they are likely to have team climates that promote an increased sensitivity to, and concern with, organizational traditions, rules, and procedures, which facilitate both the evaluation of which ideas are feasible given the existing rules and norms, as well as the application of ideas during the final phases of innovation. Even if there are one or two members who are culturally distant in these teams (i.e., a member or two have lower traditionalism values), the remaining team members are likely to follow existing protocols to successfully implement their ideas.

In contrast, teams with low average levels of traditionalism will not be as likely to understand how to harness the traditions of their organizations in order to effectively implement their ideas. Even if one or two members are culturally distant in these teams (i.e., a member or two have higher traditionalism values), the prevailing team climate will not support relying on existing, traditional protocols for idea implementation. Therefore, we hypothesize:

Hypothesis 2. The average level of team traditionalism is positively related to idea 


\section{implementing (determining a feasible set of ideas and applying them) in teams.}

Our theorizing thus far considers only how the average level of team traditionalism may affect teams' idea generating and idea implementing. Yet, innovation teams are often purposefully built to be diverse in order to increase the chance that members will bring into their team the type of divergent information that can increase the breadth of ideas and prevent group think (Gibson \& Gibbs, 2006; Janis, 1977). However, this also means that innovation teams may also be diverse with regard to their members' cultural values, and more specifically, with regard to individuals' level of traditionalism.

For several reasons, we argue that diversity on team traditionalism will be positively related to idea generating. The generating of novel ideas is facilitated by divergent processes, including expansiveness and breadth of thought, open debate, and constructive controversy (Tjosvold, 2008). These processes are encouraged when there is diversity of thought processes and cognitive styles on a team (Stahl et al., 2010). The information/decision-making perspective of diversity suggests that members of diverse teams have access to broader informational networks and thus are able to obtain a great range of ideas and information (Williams \& O'Reilly, 1998). van Knippenberg, De Dreu, and Homan (2004) theoretically argued that in order for diversity in teams to translate into positive team outcomes, members will need to effectively engage in information elaboration and provide different perspectives, which will be much more likely in teams with members holding those different viewpoints and values.

Members of diverse teams are also more likely than those of homogeneous teams to have greater variance in skills, abilities, information, and knowledge (Williams \& O'Reilly, 1998). Teams with high diversity on traditionalism have some members who strongly wish to preserve the status quo and other members who instead strongly wish to break precedent, seek new ideas, 
and embrace change. At the nexus of these differences is where breakthrough-thinking and creative idea generating in teams generally occurs (Tziner \& Eden, 1985). Consistent with this, scholars have noted that diversity of thought spurs creative abrasion (Leonard \& Straus, 1997; Stanko \& Gibson, 2009), and pushes "team members to discuss issues in more detail, fleshing out alternative perspectives and broadening their perspectives...in debating about what the right conclusion is, there is the possibility for new ideas, possibly innovative ones to emerge" (Cronin, Bezrukova, Weingart, \& Tinsley, 2011; p. 843). Based on the above logic, we predict:

\section{Hypothesis 3. Diversity on team traditionalism is positively related to the innovative quality of ideas generated in teams.}

In contrast to the above, we argue that diversity on team traditionalism will be harmful for idea implementing. Specifically, both the narrowing of ideas to a feasible set and applying them are convergent processes, which consist of compromise, negotiation, integration, and agreement as ideas are evaluated, feasibility is assessed, ideas are sold to others, and resources are secured. These processes are facilitated by similarity and commonality in thought processes and cognitive styles (Stahl et al., 2010). Teams in which members have a similar level of traditionalism are at an advantage in that convergence on the feasible set and how to apply these ideas comes more easily. For example, a team in which all members are low on traditionalism would likely agree on ideas that support status quo or only very incremental change, and hence there would be little difficulty in determining a feasible set of these ideas and applying them.

In contrast, teams with some members high, and others low, on traditionalism will likely have more difficulty agreeing on feasibility, processes, and means of implementing new ideas. For example, those lower in traditionalism, who again value the status quo, will likely prefer a slower pace, more deliberative processes for considering feasibility, and more incremental implementing of new ideas compared to those higher in traditionalism, who strongly value 
change. In addition, teams with higher, rather than lower, diversity on team traditionalism, will likely have higher levels of dysfunctional conflict (cf. De Dreu \& Weingart, 2003). Thus, even though diversity on team traditionalism serves idea generating well, it is likely to have the opposite effect on implementing ideas. Therefore, we hypothesize:

\section{Hypothesis 4. Diversity on team traditionalism is negatively related to idea implementing (determining the feasible set of ideas and applying them) in teams.}

\section{The Mediating Effects of Process Conflict}

Even though we argue that the effects of level of team traditionalism will have direct effects on both idea generating and idea implementing, we also acknowledge that team process conflict will mediate the relationships between diversity on team traditionalism and these outcomes. Indeed, a great deal of diversity research suggests that internal team processes (i.e., "members interdependent acts that convert inputs to outcomes through cognitive, verbal, and behavioral activities directed toward organizing taskwork to achieve collective goals; Marks, Mathieu, \& Zaccarro, 2001, p. 357) mediate team diversity effects. Several team processes could be theoretically argued to be responsible for the relationships between diversity on team traditionalism and outcomes, but we focus on team process conflict for several reasons.

First, conflicts about process have often been linked to information and knowledge differences in teams (Kozlowski \& Bell, 2013), suggesting process conflict is important for understanding effects of diversity. Second, our outcome of interest, innovation, is heavily influenced by the manner in which team members approach divergent thinking and the resulting conflict that emerges. Third, although research indicates the effects of task conflict (i.e., "awareness of differences in viewpoints and opinions pertaining to a group task"; Jehn \& Mannix, 2001, p. 238), are typically negative, process has demonstrated both positive and negative effects. Given innovation consists of two components (generating and implementing) 
that require very different mechanisms to achieve, process conflict may therefore be more relevant than task conflict, as it may be beneficial for some aspects of innovation (i.e., during idea generating) and a liability for others (i.e., during idea implementing).

Specifically, we argue that diversity on team traditionalism will be positively related to process conflict, which will, in turn, also be positively related to idea generating. Members in a team who vary in the value they place on maintaining the status quo versus championing new ideas and embracing change will likely engage in a great deal of debate about how they should approach accomplishing their tasks (Gibson, 1997). Different perspectives about how work should be accomplished will likely lead to higher levels of debate and discussion in a team, including about the optimal way to solve problems and accomplish tasks. In contrast, at low levels of diversity on team traditionalism, members will be more likely to agree on the processes by which their work gets accomplished. As a result, this shared perspective on work accomplishment will be associated with much lower levels of team process conflict.

However, process conflict, in turn, is likely to result in a greater number of suggestions and alternatives compared to teams with members having the same traditionalism values. As noted, diversity of thought created by variance on traditionalism values is associated with creative abrasion (Leonard \& Straus, 1997), which is linked to members having to consider alternative points of view and assess each of these views independently. Such debates, discussions, and disagreements likely produce a wider number of divergent perspectives and views associated with higher level of idea generating. Thus, we predict:

\section{Hypothesis 5. Team process conflict mediates the relationship between diversity on team traditionalism and idea generating.}

Regarding the relationship between diversity on team traditionalism and idea implementing, the conflict management literature has suggested that intense levels of team 
process conflict can impede teams from coming to the agreement needed to accomplish tasks (Behfar, Mannix, Peterson, \& Trochim, 2002; Jehn \& Bendersky, 2003). For example, teams with high levels of process conflict are likely to be characterized by: (a) disagreements about who should do what in the team; (b) debates about who is responsible for what tasks; and (c) arguments about the best way to allocate resources (Jehn \& Mannix, 2001). Process conflicts have been shown to distract group members' resources or attention from task engagement (Jehn, 1995) and impair group commitment to a task (Behfar et al., 2011). If members cannot agree on the elements of basic team functioning, such as members' roles, task responsibilities, and resource allocation, those teams would be much less likely than teams with fewer disagreements to be able to converge on determination of feasibility and actually then implement the ideas that are generated (cf. Wageman, 2001). Indeed, idea implementing requires that members agree on the norms, rules, roles, and methods by which their team should accomplish its tasks. Members will also need to obtain support and resources for their ideas in order to judge their feasibility and make them implementable (Knudsen \& Levinthal, 2007), which becomes much more of a challenge when members are engaged in high levels of process conflict. As a result, we predict:

\section{Hypothesis 6. Team process conflict mediates the relationship between diversity on team traditionalism and idea implementing (determining the feasible set of ideas and applying them) in teams.}

\section{Method}

\section{STUDY 1: A FIELD STUDY}

To test our hypotheses, we analyzed survey data collected from engineering project teams in the aerospace industry. The teams were formed to work on a $\$ 200$ billion USD contract to design a state-of-the-art innovation to be employed in a next-generation military aircraft. Generating of ideas and feasibility of implementing was the explicit goal. Teams were each multinational, of about the same size and scope, and each had been in existence for one year, 
thus holding variables constant that, in the past, have been known to influence innovation (Gibson \& Gibbs, 2006). Few team studies have allowed for controlling for such factors. We used quantitative survey-based measures with team members to capture the independent variables. The dependent variables, idea generating and idea implementing, were rated by multiple customers and stakeholders external to each of the teams. Hence, using different sets of informants for the independent and dependent variables provided a rigorous test of the hypotheses.

\section{Sample}

Our sample included a total of 266 individuals, representing 56 engineering project teams. The average team size was six members, ranging from four to eight members. Responses were obtained from an average of five members per team (ranging from 4-8 responses), for an overall response rate of 79 percent. In those instances where we did not have $100 \%$ of team members responding, the members who did not respond were not in attendance on the day of the survey, and these absences from work were completely at random. That is, our consultation with HR suggested that they were absent due to vacation and illness -- random factors, not correlated with a willingness to complete our survey. Likewise there is no reason to believe these absences would be correlated with any responses they might have provided on the survey. The HR records indicated, for example, that these missing respondents shared similar demographic characteristics to people who did attend work on the day of the survey. In accordance with the literature on missing data, this provides reassurance that these respondents are missing completely at random because the factors that lead them to be missing (e.g., illness) are orthogonal to the study hypotheses and sampling procedures, reducing the concern over any discrepancies, should they have also participated in the study (Enders, 2010; Peugh \& Enders, 
2004). We also note that the $79 \%$ response rate is actually quite high in field research with teams, where it is incredibly rare to be able to include every member of a team (e.g. Carton \& Cummings, 2013; De Dreu, 2007; Gardner et al. 2012).

Although our focus is on cultural values, rather than demographics, the sample was diverse in terms of age, tenure, functional background and nationality. Average age of team members was 39 years, ranging from 19 to 66 years of age, and 87 percent of the sample was male. The average tenure with the organization was 11.04 years, ranging from less than one year to over 39 years; and $48 \%$ come from Design Engineering functions, 21\% from Manufacturing Engineering functions, 20\% from Stress Analysis, 4\% from Finance, 2\% from Mass Properties Engineering functions, $2 \%$ from $\mathrm{HR}, 1 \%$ from IT, and $2 \%$ from other functional backgrounds. Participants' nationalities included U.S.A (49\%), the England (29\%), Vietnam (4\%), China (4\%), and then 2\% each Japan, Philippines, Korea, Mexico, Germany, Poland and the Netherlands. Participation was strictly voluntary. Discussions with internal organizational representatives ensured that the sample was representative of the population in terms of age, gender, profession, and tenure, therefore indicating no evidence of non-response bias.

\section{Procedure}

The survey, capturing a variety of individual and team perceptions, was administered to all team members. A separate survey capturing team outcomes was administered to two to three customers per team, over a period of approximately four weeks. These customers were selected by the overall program leader of the initiative, who was two hierarchical levels above the team members. The customers were employees of the organization, but downstream in design and production, and had a thorough understanding of both the goal of the program and had expertise in each team's work. The customers received the designs of the teams under investigation, and 
these designs were then used in the production process. Hence, they were uniquely capable of assessing the innovative quality of the ideas generated, as well as the implementation of the ideas, which includes both the feasibility and application. The customer ratings are therefore based on their expert evaluation after having implemented the teams' output. Teams varied in terms of their degree of traditionalism, but they did not vary significantly in terms of task type. All teams rated their design tasks as non-routine (mean=3.66 on a 5-point scale; $\mathrm{SD}=.52$ ), and ANOVA tests established no significant difference between teams in task routineness $(\mathrm{F}=.90$, n.s.).

\section{Measures}

Traditionalism. We assessed traditionalism using a three-item scale based on Schwartz's (1994) longer survey scale, that asked the extent to which team members agreed with the following: "I believe a company's rules should not be broken, even when the employee thinks it is in the company's best interest", "I am eager to take on new or challenging task assignments (reverse-coded)", and "I am willing to make constructive suggestions to improve the operations of the company (reverse-coded)." Participants rated each of these items on a scale that ranged from $1=$ Strongly Disagree to $5=$ Strongly Agree. Cronbach's alpha was 0.75 .

Diversity on team traditionalism. Consistent with our theoretical treatment of diversity on traditionalism as a type of separation diversity (Harrison \& Klein, 2007), we assessed the variance in team traditionalism as the standard deviation of traditionalism within each team, such that smaller values indicate proximity, and larger values indicate greater disparity. The minimum value was .25 , indicating that all members held relatively similar views on traditionalism, and the maximum value was 1.60 , indicating that some members were high on traditionalism, and other member extremely low on traditionalism. The mean variance across all teams was .60 and the 
standard deviation was .32.

Team process conflict. Team process conflict was measured using a three-item scale adapted from validated scales of process conflict in teams (Jehn \& Mannix, 2001; Behfar et al., 2010). Items included the following: "How frequently do members of your team disagree about the way to complete a group task?", "How often do members of your team disagree about who should do what?", and "To what extent are there differences of opinion in your team?" Participants rated each of these items on a scale that ranged from $1=$ Not at All to $5=$ A Lot. Cronbach's alpha was 0.94.

Dependent variables. To capture the distinction between idea generating and idea implementing, we asked the customers to rate each team using a scale which ranged from $0 \%$ $100 \%$, with the score representing percent the team had achieved compared to what was possible. The customers first rated the extent to which the team had been innovative with regard to generating new ideas for their design, and then secondly they rated the extent to which the team had achieved high technical performance in the implementing their ideas, indicating that the team had determined a feasible set of ideas and applied them. The mean for idea generating was 79.74, s.d. $=10.70 ;$ and, the mean for implementing was 80.31, s.d. $=9.11$.

Controls. We included six control variables. The first two of these variables have been shown to have an impact on team outcomes in prior research, as well as shown to vary across teams that may have different levels of cultural values. Thus, they may represent alternative explanations for effects on innovation (e.g., Campion, Medsker, \& Higgs, 1993; Brown \& Eisenhardt, 1995; Earley \& Gibson, 2002). To account for the fact that larger teams may have more difficulty reaching shared understanding and innovation, we controlled for team size, as captured by the number of people on each team indicated by organizational records. To also 
account for differences in the quality of leadership that may exist outside the team which may affect innovation, we controlled for external leadership using three items that capture the extent to which the team was guided by external leadership (e.g., "Our leader fails to take necessary actions to ensure team effectiveness," reverse coded; $\alpha=.82$ ).

We also included controls for gender and age diversity ${ }^{2}$ within each team, which are demographic factors that may align with traditionalism or influence power dynamics in a group, and hence could impact idea generating or idea implementing in a team. We measured gender diversity by calculating categorical dispersion of individual genders within each team (Blau, 1977). We standardized the index such that $\mathrm{H}=0$ signifies complete homogeneity (i.e., all team members are male) and $\mathrm{H}=1$ indicates complete heterogeneity (i.e., one half of all team members is female and the other is male). We measured age diversity was using the within-team standard deviation at the team level.

Finally, we included measures of collectivism and power distance to control for other cultural values that could have an effect on idea generating and idea implementing. We measured collectivism using a condensed version of the scale by Erez and Earley (1993) consisting of four items (e.g., "being part of a team has important benefits for work") that ranged from $1=$ Strongly Disagree to $5=$ Strongly Agree. Reliability (alpha) was 0.83. We measured power distance using a three-item scale condensed version of the scale developed Earley and Erez (1997) (e.g., "in work-related matters, managers have a right to expect obedience from their subordinates) that ranged from 1 = Strongly Disagree to $5=$ Strongly Agree. Reliability (alpha) was 0.75.

\section{Results}

We conducted a confirmatory factor analysis (CFA) to test whether the measures we used are distinguishable from each other. Results indicated that a five-factor baseline model composed 
of traditionalism, team process conflict, external leadership, collectivism, and power distance fit the data adequately $(\mathrm{RMSEA}=.06, \mathrm{CFI}=.94, \mathrm{IFI}=.94)$, providing evidence of the discriminant validity of the measured variables. The means, standard deviations, and correlations for all variables appear in Table 1. Table 2 shows the results of our tests of the hypotheses, which we conducted via hierarchical regression analysis with control variables entered in Step 1 and level of team traditionalism and traditionalism diversity entered in Step 2. For our tests of mediation, we utilized the PROCESS program for SPSS (Hayes, 2013), as outlined below, which utilized bootstrapped samples to generate $95 \%$ confidence intervals of the overall indirect effects.

Insert Table 1 and 2 about here

Hypothesis 1 stated that the level of team traditionalism would be negatively related to ratings of idea generating, and Hypothesis 2 stated that the level of team traditionalism would be positively related to ratings of idea implementing. As seen in Table 2, we found full support for Hypothesis $1(\beta=-.21, \mathrm{p}<.05)$ and Hypothesis $2(\beta=.22, \mathrm{p}<.05)$. This suggests that teams with values largely supporting the status quo and adherence to tradition may be less able to generate new ideas; yet, these same teams are able to work within the known bounds of the organization to determine how to implement a feasible set of innovative solutions.

Hypothesis 3 stated that diversity on team traditionalism would be positively associated with ratings of ideas generated, and Hypothesis 4 stated that diversity on team traditionalism would be negatively associated with ratings of idea implementing. As seen in Table 2, we found full support for both Hypothesis $3(\beta=.19, \mathrm{p}<.05)$ and Hypothesis $4(\beta=-.25, \mathrm{p}<.05)$. Results suggest that teams composed of some members high on traditionalism, and other members relatively low on traditionalism, are able to be more effective in generating novel and creative ideas. On the other hand, we found that teams with members having a mix of high and low 
traditionalism were less effective at idea implementing.

We next examined the indirect effect of diversity on team traditionalism on idea generating (Hypothesis 5) and idea implementing (Hypothesis 6) through team process conflict. To analyze this effect, we used the PROCESS program for SPSS (Hayes, 2013), employing bootstrapped samples to generate $95 \%$ confidence intervals of the overall indirect effect. We found a significant positive effect of team process conflict on idea generating $(b=.22$, se $=.12, p$ $<.05)$ and a significant negative effect of team process conflict on idea implementing $(b=-.33$, $\mathrm{se}=.06, \mathrm{p}<.01)$, as predicted. Further, we found a significant indirect effect of diversity on team traditionalism on idea generating through team process conflict (.14), with a confidence interval that did not cross zero $[.0032, .3248]$, as well as a significant negative indirect effect of diversity on team traditionalism on idea implementing through team process conflict (-.27) with a confidence interval that did not cross zero [-.6581, -.0246]. These results provide support for Hypothesis 5 and 6.

Robustness checks. To verify the robustness of our models, we conducted two additional analyses. First, we entered alternative cultural values, beyond traditionalism, that have often been included in past research. These were not hypothesized as having effects, and indeed, analyses revealed that even after controlling for individualism-collectivism and power distance, we found the predicted differences in our sample (see Table 2). This suggests that our theoretical basis for choosing traditionalism among the many potential cultural values was supported. Finally, to address any concerns regarding the team members who were not able to complete the survey due to absence from work, we entered into the data base for them the mean values on the hypothesized variables and repeated the main tests of hypotheses and our results remained the same. 


\section{STUDY 2: AN EXPERIMENTAL TEST}

\section{Rationale for Study 2}

To further examine the role of team cultural values and team diversity on innovation, we conducted a second study in an experimental setting in which both idea generating and idea implementing were again the explicit goals. This study allowed us to validate our findings from Study 1, as well as rule out alternative explanations in a more controlled setting. Specifically, post hoc analysis of Study 1 data indicated that using the midpoint of the traditionalism scale and the mean variance as cut off values to create four cells, many teams in Study 1 were disproportionately clustered into certain cells (for instance, 20 teams had a low average and high variance, while only four teams had a high average and high variance). Hence, we were concerned that our tests were conservative and failed to capture the full range of compositional options, and we were familiar with instances in which understanding teams such as those with high levels and high diversity on traditionalism is important.

Consider, for example, a team consisting of human resource and organizational development professionals working across locations in East Timor and Australia, charged with developing a new training program. There may be a several members very high on traditionalism, one member very low on traditionalism, and one member may be at the mid-point on traditionalism. This configuration results in a high overall level of traditionalism and high diversity on traditionalism for this team. The traditionalists may resist new approaches to training programs suggested by those low on traditionalism, for example, using a virtual format for the training. Rather than embracing change, more traditional members may recommend a program that looks very similar to those offered in the past, even though the team was given a mandate to develop and implement a new training program. Yet, to the team's benefit, those high on 
traditionalism may have important points relevant to feasibility (e.g., virtual programs may be difficult in their context, and there may be good arguments for a status quo implementing using a face to face approach). Thus, although relatively silent during idea generating, they may be helpful during implementing, and in particular in terms of increasing the feasibility of the implementation. This is an example of a team that benefits from a high level of traditionalism, particularly during implementing, while at the same time, the diversity on traditionalism enables a few new pieces of content incorporated into the training, and the team accomplished their objective of developing a new program.

The experimental setting in Study 2 enabled us examine such instances because we were able to purposefully compose teams based on traditionalism values to maximize the betweenteam differences in the average level of, and diversity on, team traditionalism, such that there were an equal number of teams that had a high average/high diversity, low average/low diversity, low average/high diversity, and high average/low diversity scenario. We also selected a task for which we could isolate the determining feasibility facet of implementing ideas, hence our dependent variable is focused more precisely as this facet.

\section{Method}

We conducted an experiment with teams of MBA students doing a team project at a large private university in the Northeastern U.S. The sample consisted of 332 students who, prior to the study, were asked to complete a short survey with questionnaire items measuring their cultural values, including traditionalism. Participants were also asked general demographic information. The age of participants ranged from 26 to 33 years, and their mean age was 28 (s.d. =3.6). Thirty-four percent of the participants were female; 62 percent were Caucasian; 22 percent were Asian; 10 percent were African American; and 6 percent were Hispanic. 
We formed a total of 62 teams, each with a minimum of four to a maximum of six members. Mean team size was 5.4 members (median $=5$ ). We employed a two-by-two factorial design, in which we purposely formed teams to create high vs. low average levels of team traditionalism and high vs. low diversity on team traditionalism (see below for measurement of traditionalism). ${ }^{3}$ Specifically, we assigned study participants to teams so that they belonged to one of four experimental conditions based on team composition: (1) high average/ high diversity (i.e., average level of team traditionalism greater than 3.5; team standard deviation on traditionalism above 1.0); (2) high average/low diversity (i.e., team average level of traditionalism greater than 3.5; team standard deviation on traditionalism below 0.5); (3) low average/high diversity (i.e., team average level of traditionalism less than 2.5; team standard deviation on traditionalism above 1.0); or, (4) low average/low diversity (i.e., team average level of traditionalism less than 2.5; team standard deviation on traditionalism below 0.5 ). These values represent the midpoint of the scale for traditionalism (i.e., 3.0) and the median standard deviation on traditionalism (i.e., .78), while also accounting for a threshold above and below that, to provide a more conservative cutoff for experimental conditions, such as would be suggested in a regression discontinuity design (e.g., Imbens \& Lemieux, 2008).

Each team began by watching a 1-minute informational video on 3-D printing technology, so they would be familiar with how the technology worked. Then, each team was told that they would be assisting a technology company in developing potential new products to include in their product offering. Working collaboratively, each team was first asked to generate new ideas for applications of the 3-D printing technology for the company. The teams were instructed that they would receive 10 minutes to generate and record their ideas.

After this idea generating phase, teams were given an additional three minutes to select 
the idea they deemed to be the most promising. Teams were specifically instructed to determine promise based on three factors - the idea's overall novelty, likelihood of success, and profit potential - so that the team goal included both an idea generating component, as well as an idea implementing component, specifically focusing on the feasibility facet of implementing ideas. Finally, each team presented their selected idea to two external raters, who evaluated each of the selected ideas and subsequently completed ratings for each team idea. Raters were external experts from large corporations that engage in frequent innovative projects and processes within their own organizations. Raters were initially invited as guest speakers on the topic of 'Innovation: Idea Generation and Idea Evaluation'; therefore, following their participation as raters, they spoke on this topic and helped debrief the study. As these raters engage in innovation projects within their own organizations, and have seen the types of projects that are accepted or rejected in their markets, we deemed them to have sufficient expertise in making their assessments.

\section{Measures}

Traditionalism. Traditionalism was measured using the same three-item scale from Study 1. Participants rated each of these items on a scale that ranged from $1=$ Strongly Disagree to $7=$ Strongly Agree. Reliability (alpha) was 0.83. Again, diversity on traditionalism was captured using the standard deviation of traditionalism scores in each team. In addition, to provide validity of our measure of traditionalism, participants were also asked to rate themselves on a sliding scale which ranged from 0-100, with one end of the scale indicating "I place great importance on the traditional ways of doing things" (0), and the other end of the scale indicating "I place great importance on breaking precedent and forging new approaches" (1). This allowed us to capture and isolate traditionalism vis-à-vis a distinction with modernity. 
Idea generating. To capture the generating of creative ideas within each team, the two external raters assessed the extent to which they agreed that the team's initial list of ideas were "original", "novel", and "creative" ideas on a scale that ranged from $1=$ Strongly Disagree to $5=$ Strongly Agree. Following Perry-Smith and Coff (2011), we instructed these external raters to consider a number of factors in making their assessments, including a pure count of ideas they deemed original, novel, or creative, as well as the total number of unique ideas the team produced that were not duplicated by other teams. Inter-rater correlation was high (.86).

Two separate external raters, also from firms known for innovation within their organizations, were subsequently asked to assess the extent to which the team's selected idea (i.e., the idea that they presented) was "original", "novel", and "creative." These ratings were again made on a scale that ranged from $1=$ Strongly Disagree to $5=$ Strongly Agree, and raters were asked to consider in their assessments those ideas that were redundant. Inter-rater agreement was high $(r=.80)$, as was agreement between the former and latter ratings of creative idea generating $(r=.89)$. Therefore, ratings based an average of the two ratings on the final presented idea was used in the analyses.

Idea implementing - feasibility. We assessed the feasibility facet of idea implementing using a three-item scale adapted from Baer (2012). Each of the external raters assessed the extent to which they agreed that "the team's idea would be approved for further development within an organization", "the team's idea could be transformed into usable products, processes, or procedures", and "the team's idea could successfully be brought to market or be successfully implemented at an organization", using a scale that ranged from $1=$ Strongly Disagree to $5=$ Strongly Agree. Inter-rater agreement was again very high $(\mathrm{r}=.78)$, and as such, an average of the two ratings was used. 


\section{Results of Study 2}

The means, standard deviations, and correlations for all variables appear in Table 3.

To test Hypothesis 1 and 2, we used Analyses of Variance (ANOVA) to ascertain whether there was significant between-team discrimination in ratings of teams' idea-generating and ideaimplementing feasibility. One-way ANOVA results showed significant between-team differences in teams with high average levels of traditionalism versus low average levels of traditionalism (see Table 4). Teams with high average levels of traditionalism were rated lower on idea generating $($ mean $=2.93$, s.d. $=.94)$ compared to teams in the low average levels of traditionalism condition $($ mean $=3.44$, s.d. $=1.13, F[1,60]=3.60, \mathrm{p}<.05)$, in support of Hypothesis 1. Teams with high average levels of traditionalism were rated higher on implementing feasibility (mean $=3.98$, s.d. $=.81)$ compared to teams in the low average level of traditionalism condition $($ mean $=2.51$, s.d. $=.77, F[1,60]=53.37, \mathrm{p}<.01)$, in strong support of Hypothesis 2.

Results also showed significant between-team differences in teams with high (rather than low) levels of diversity on team traditionalism for ratings of teams' idea generating and implementing feasibility. One-way ANOVA results showed that teams with high levels of diversity on team traditionalism were rated higher on idea generating $($ mean $=3.94$, s.d. $=.67)$ compared to teams with low levels of diversity on traditionalism (mean $=2.40$, s.d. $=.81, F[1$, $60]=66.40, \mathrm{p}<.01$ ) in support of Hypothesis 3 (see Table 5). Finally, teams with high levels of diversity on team traditionalism were also found to be rated lower on implementing feasibility $($ mean $=2.93$, s.d. $=1.14)$ compared to teams with high level of diversity on traditionalism $($ mean $=3.53$, s.d. $=.93, F[1,60]=5.24, \mathrm{p}<.05)$ in support of Hypothesis 4 (see Table 5). Insert Tables 3-7 about here 
In the contrast test between individual cells, the two-way ANOVA demonstrated support for the contingent relationship between teams that may be designed for successful idea generating and teams that may instead be better suited for successful idea implementing feasibility (see Tables 6 and 7). As seen in Figure 2, ratings of idea generating were highest for the teams low on average level of traditionalism and high on diversity on team traditionalism $($ mean $=4.38$, s.d. $=.50)$, but these same teams were rated relatively low on implementing feasibility $($ mean $=2.08$, s.d. $=.17)$. Similarly, ratings of implementing feasibility were highest for teams high on average level of traditionalism and low on diversity on team traditionalism $($ mean $=4.21$, s.d. $=.20)$, but these same teams were rated low on idea generating $($ mean $=2.29$, s.d. $=.91)$. Teams high on average level of traditionalism and high on diversity on team traditionalism have relatively high ratings of both idea generating (mean $=3.50$, s.d. $=.52)$ and implementing feasibility $($ mean $=3.77$, s.d. $=1.08)$, but still perform worse than either of the former teams, suggesting that there tradeoffs between performance and team composition. We discuss this finding in more detail below, and consider some of the implications of this tradeoff for organizations seeking to successfully innovate.

\section{Insert Figure 2 about here}

\section{DISCUSSION}

To successfully innovate, organizations are increasingly devoting resources to teams that can help develop and implement novel and useful ideas. In our study, we found that how these teams are assembled may be a more noteworthy challenge than simply building teams that incorporate the views, skills, and expertise of a diverse range of members (Watson et al., 1993). Answering the call to more fully examine aspects of cultural diversity in teams (Gibson et al., 2014), we investigate a specific cultural value that has immense salience for innovation-based 
activities - traditionalism. In both a field study and laboratory setting, we find that whether traditionalism is beneficial to team innovation depends on whether: (1) team members' level of traditionalism or their diversity on this is examined and (2) idea-generating versus ideaimplementing is of primary importance. We discuss theoretical and practical implications of these findings for teams engaged in generating and implementing ideas.

\section{Theoretical Implications}

Our findings make several theoretical contributions to the areas of teamwork and innovation. First, our research extends the previous work on cultural values by specifying the role that traditionalism plays in team innovation. Rather than focusing on cross-national comparisons (Leung et al., 2005; 2011), or oft-studied cultural values such as individualismcollectivism or power distance, we examine traditionalism as a value that has particular salience in modern work settings that seek more innovative, entrepreneurial strategies.

The extent to which employees embrace traditionalism, defined as the importance that employees place on existing organizational practices and norms (Schwartz, 1994), likely has consequences for how new initiatives within an organization are proposed or accepted; and, these new ideas create change. Importantly, our study also reinforces the need to examine both the average level and dispersion around a given value, demonstrating that these characteristics of teams may have very different (even opposite) effects. Therefore, our work provides theoretical grounding on a value that may be very important for today's teams (Gibson et al., 2014) and suggests that future research could shed light on the importance of including both average level of, and diversity on, traditionalism to increase our understanding of how varied cross-cultural interfaces, varied team compositions, and distinct measures of team innovation might intersect. Second, we unpacked the innovation construct in order to better understand how the 
cultural composition of a team with regard to traditionalism might be differentially related to the two main dimensions of team innovation - idea generating and implementing. Previous studies examining the culture-innovation link theorized about the overall construct of innovation (Kirkman et al., 2006), which may have obscured the more fine-grained predictions generated by separating out these two innovation dimensions. That innovation is comprised of sub-phases involving idea generating and implementing has long been recognized in the team innovation literature (West, 2002). Consistent with this, we theorized that the team processes involved in generating ideas are separate and distinct from those of implementing ideas. As a result, we hypothesized (and empirically verified) that the average level of, and diversity on, team traditionalism related in opposite ways to idea generating and implementing. Again, this would not have been possible had we theorized about and examined innovation in its gestalt form.

Regarding the average level of team traditionalism, both of our studies demonstrated that the extent to which a team's members are, on average, higher versus lower on team traditionalism can either be positive or negative for team innovation. The difference lies in what phase of innovation is of interest. For idea generating, teams were not as able to produce ideas when the central tendency was toward values consistent with honoring and protecting the status quo (i.e., higher average levels of team traditionalism). Such values impeded the processes associated with idea generating, such as seeking novelty or being open to the uncertainty around whether new ideas will be likely to succeed and be valuable. In contrast, those lower in traditionalism value a sense of openness about creativity without a preoccupation with ambiguity. For idea implementing, our findings revealed the opposite relationship; that is, for teams with a higher, rather than lower, average levels of traditionalism were more effective at idea implementing. In other words, the very value systems that would hamper the generating of 
ideas actually promote implementing. For example, idea implementing requires adherence to rules and protocols more so than idea generating, in the form of critical evaluation, understanding and navigating organizational structures, and getting resources and support necessary for implementing (Knudsen \& Leventhal, 2007). More traditional values are consistent with these important processes necessary for implementing.

Regarding diversity on team traditionalism, both of our studies showed that the dimensions of innovation are differentially affected, and that the differential relationships are opposite to those for average levels of team traditionalism. That is, we found that diversity on team traditionalism is positively related to idea generating but negatively related to idea implementing; and, this was true whether the operationalization of idea implementing included both feasibility and application of ideas (Study 1) or just focused on feasibility (Study 2). Our findings extend and integrate theories of cross-cultural psychology with the information/decision-making perspective on diversity. Even though idea generating benefits from diversity on traditionalism and team member differences to facilitate brainstorming and combinatory processes (Weick, 1979; Paulus \& Yang, 2000; Hargadon \& Bechky, 2006), implementing these ideas profits from mutual understanding and consistent expectations surrounding execution, which likely arises from homogeneity. We also used the information/decision making perspective on diversity to argue that team process conflict would mediate the relationships between diversity on team traditionalism and both idea generating and implementing. Such findings support previous research on team diversity that demonstrates that team composition is a more distal team input that influences team outputs through more proximal team processes (van Knippenberg et al., 2004; van Knippenberg \& Schippers, 2007), but extend this literature by showing effects specifically on innovation . 
Our findings also provide a useful contribution to those who study the complex interdependencies of innovation (e.g. Gann, 2000), as well as the role of teams that are assembled specifically to serve organizational goals to innovate (De Dreu \& Weingart, 2003; Pearce \& Ensley, 2004; Gibson \& Dibble, 2013). It may be that individuals are able to engage in both idea generating and implementing activities successfully and even synergistically - as experimental research shows that thinking about generating (i.e., novelty) and implementing (i.e., usefulness) concerns simultaneously can increase creative idea generating (Miron-Spektor, Gino, \& Argote, 2011). Other recent research supports the notion that some people have a cognitive style that supports efforts towards idea generating as well as implementing (West \& Anderson, 1996; Barry \& Stewart, 1997; Taggar, 2001; Miron, Erez, \& Naveh, 2004; MironSpektor et al., 2011). Additional research should explore this possibility in work teams, in field settings, and use longitudinal designs to dynamically capture change over time.

Finally, we provide a useful lens for the entrepreneurship literature on team innovation (e.g. Brinckmann, 2008; Teal \& Hofer, 2003; Vanaelst, Clarysse, Wright, Lockett, Moray, \& Jegers, 2006). These scholars have begun to recognize the importance of team composition. Overwhelmingly, founding teams tend to be homogenous; that is, of the same gender, race, experience, and backgrounds (Ruef, Aldrich, \& Carter, 2003), and team members tend to be alike for a variety of reasons, including homophily (i.e., individuals tend to like people who are similar), shared networks, and common experience. Prior research demonstrates that there are real benefits to having similarity within teams. For example, these teams may be able to act more quickly than diverse teams and are more exploitative in their strategies (Beckman, 2006) and may tend to be more harmonious as well (Aldrich \& Ruef, 2006). Our findings demonstrate that an additional benefit may exist. Teams with members that are broadly similar in terms of a 
common cultural value such as traditionalism may also have a common basis for communication and are better able to come to mutual understandings about how to implement within the bounds of an organization and the best ways to go about doing so. On the other hand, for entrepreneurial startups that are looking to develop innovation by bringing to market more radical ideas, our research suggests that diversity on traditionalism can be an advantage.

\section{Practical Implications}

Because we found that the average level of traditionalism and diversity on traditionalism have opposite effects for idea generating vs. implementing, there are several steps that team leaders in organizations can take to make sure that that these two facets of innovation are successfully executed. The first possibility is to put one type of team in charge of generating ideas and another type in charge of implementing them. Specifically, for idea generation, teams should be composed such that they have low average levels of, but high diversity on, traditionalism. In contrast, for idea implementation, teams should be composed such they have high levels of traditionalism, but low diversity on traditionalism. Of course, composing teams in these ways requires that team leaders assess their members on traditionalism and then build teams with these traditionalism profiles. A variety of tools exist for examining cultural values (see Leung et al. 2011 for a review).

If, however, the only option is to have the same team generate and implement ideas, team leaders could change the composition of such a team when moving from the generating to implementing phase. For example, a leader could remove a few members who scored relatively low on traditionalism, as they would likely struggle more in the implementing phase. This scenario would create the right mix of a high average level of, and low diversity on, team traditionalism that might enable such a team to better implement. 
Rather than using selection tools to build teams with the right mix of traditionalism values, another option is to use training and development programs to create new idea generating skills among those that are more predisposed to idea implementing, as might be the case for those high in traditionalism. For example, policy analysts in China bemoan the fact that the contribution of innovation to economic growth in the past three decades has been very small, and there is still a considerable gap between China and other advanced economies in terms of innovation resources and capacity (Wu, 2010). Many Chinese (although certainly not all) have a tendency to endorse traditionalism, and in our study, these values were negatively associated with idea generating in teams.

According to developmental psychologists, growing the capacity for idea generating may imply educational reform, so that creative play is incorporated into curriculum for early learners, who can then carry this capacity into the workplace in their adult lives, to enhance innovation. Some U.S. based-organizations have experimented with such practices, with interesting successes chronicled in the business press. For example, at Google, employees are given one day a week to spend time on side projects that allow them to engage in free-thinking, imagination, and innovation, but within broad directions that are strategically-defined by the company (Kotter International, 2013). Although not specifically addressing traditionalism, they have developed playful environments that encourage creativity, with innovative new product development as an end result.

Finally, we found that process conflict explains why diversity on traditionalism is associated with idea implementing. When team composition is fixed (and the team members vary on traditionalism), then techniques for reducing process conflict are likely to improve implementing processes. For example, following a meeting or major milestone, reflective 
activities focused on potential shortcomings in team processes can help to counteract complacency (Ellis, Mendel, \& Nir, 2006; Dibble \& Gibson, 2013). Research has also shown that teams that are encouraged to develop alternative plans of action avoid deleterious effects of cognitive entrenchment (Uitdenwilligen, Waller, \& Pitariu, 2013: Gibson \& Dibble, 2013).

\section{Limitations and Future Research}

As with all research, out study is not without limitations. First, we focused solely on the cultural value of traditionalism (even though we did at least control for the more commonly examined values of individualism-collectivism and power distance) because we argued this cultural value in particular was the most tightly theoretically connected to innovation. Even though we used theory as our guide to select traditionalism, clearly individuals identities are made up of a variety of cultural values, not just a handful (Kirkman et al., 2006). Including a greater number of cultural values could have increased our confidence in traditionalism as a key explanatory mechanism even more.

Second, there are other specific cultural values that may have close ties to innovation. For example, the cultural value of uncertainty avoidance, or the extent to which people in a society rely on social norms, procedures, and rules to increase the predictability of future events (Javidan \& Carl, 2005), could have an effect on idea generating, which as stated does involve some level of comfort with ambiguity about the future. In addition, in their work on cultural tightnesslooseness, Gelfand et al. (2006) theorize about the construct of conservativism, which could be related to traditionalism. We encourage future researchers to investigate these other possibilities.

Third, another limitation of our research is that we relied on self-report, survey-based assessments of cultural values. There are growing calls for alternative assessments of individuals' cultural values, as there are many stated limitations of self-report surveys (Caprar, 
Devinney, Kirkman, \& Caligiuri, 2015). For example, cultural background can affect response styles and there are likely issues with semantics across cultures (Devinney, Auger, \& Eckhardt, 2010). Our study cannot account for the possibility that these issues might have influenced the results.

We encourage future researchers to examine cultural value composition using a variety of different operationalizations (Harrison \& Klein, 2007; Gibson et al. 2012; McDaniel \& Gibson, 2012). For example, a promising avenue might be to investigate how cultural values such as traditionalism may align with other values to create even more potent effects (Gibson, McDaniel \& Szkudlarek, 2012). It may be that it is only when traditionalism values are aligned with other cultural characteristics such as universalism (i.e., the belief that rules should be followed regardless of the circumstances or the individual(s) involved, see Trompenaars \& HampdenTurner, 1998), that we see deleterious effects on innovation. Or, a second possibility is only when traditionalism values align with low uncertainty avoidance will we see weaker effects.

Another possibility is that traditionalism values might moderate the effects of faultlines formed based on demographic or categorical variables. There is some evidence to support such a line of thinking. For example, Bezrukova et al. (2012) examined whether a result-oriented organizational culture moderated the effect of informational faultlines (i.e., based on categorical variables representing skill, knowledge, and expertise) on performance. Findings demonstrated that even though informational faultlines were detrimental for group performance, the negative relationship between faultlines and performance was reversed in cultures with a strong emphasis on results. We did not examine faultlines for cultural value diversity because saw no evidence of subgroups based on the cultural values we included, and according to recent advice, if "including faultlines in models of group processes and outcomes does not explain more than including 
diversity alone, there is no reason to theorize about and include faultlines" (Thatcher \& Patell, 2012). But these same authors do suggest that a promising avenue for future research would be to investigate whether cultural values might result in faultlines. We encourage further exploration of this issue.

It may be that certain personal characteristics interact with traditionalism to amplify the weight carried by certain individual team members' views. For example, a given team member may be more extroverted, have longer tenure in an organization, or be a skilled negotiator. This could mean that his or her level of traditionalism has a stronger influence on the team than that of other members, suggesting the importance of considering how combinations of individual characteristics create innovation dynamics in teams. Examining similar possibilities with regard to traditionalism extends cultural values research and provides even more fine-grained implications for team composition.

Finally, we used a different criterion in Study 1 (comprised of idea generation and implementation) versus Study 2 (comprised only of the feasibility element of implementation). The results across the two studies were highly consistent, however, if they had been dissimilar, we would not have been able to rule out that this may have been due to our having isolated only a specific component of implementation as the dependent variable of interest in Study 2. We were also unable to include process conflict in Study 2 due to space constraints in our survey materials. We encourage future research which includes both of the idea generation and implementation components, as well as potentially other dependent variables, such as efficiency, productivity or member satisfaction with teamwork, alongside process conflict, in order to be able to make broader claims about the outcomes associated with traditionalism diversity. 
Our study showed that there is a complex relationship between traditionalism values and innovation in teams. The opposite results for the relationships depended on: (a) which operationalization of team traditionalism was used (i.e., average level vs. diversity); and (b) which dimension of innovation was of interest (i.e., idea generating vs. implementing). Our unpacking of these two constructs made it possible for us to detect these findings and inform managers as to how to build teams to maximize both innovation dimensions.

In a comprehensive review of the future of innovation in organizations, Farr, Sin, \& Tesluk (2003:576) state, “Organizations must continually innovate in order to increase or even maintain competitiveness... with the increasing use of work groups as the basis for accomplishing work tasks in many organizations." Given that work teams are of great significance in organizational innovation, scholars have extended the importance of teams beyond the static to the realm of dynamic designs and compositions. However, extensions have generally lacked the integration of factors that impact these designs - such as how cultural values like traditionalism and cultural diversity on such values might impact team outcomes. We have attempted to clarify and shed light on the complexity associated with research on team innovation, and our hope is that our findings will spur future research on this valuable dynamic and the influence of teams on multiple facets of innovation. 


\section{ENDNOTES}

${ }^{1}$ We acknowledge that the arithmetic average in a team is influenced by extreme scores. For example, a 5person team with one high score, a mid-range score and three relatively low scores has the same average as a team composed of five mid-range scores, even though the dispersion of scores across the scale is different. Thus, although the arithmetic average is imperfect in representing the dispersion of scores, we utilize the average as way of capturing the central tendency, in order to compare that to the dispersion in the team. An alternative would be to combine these into one indicator (e.g., the co-efficient of variation), so as to account for teams that have low central tendency and also little variance, but then we lose the ability to see differential effects of the average level and diversity, which is one our study's key purposes.

${ }^{2}$ In addition to age and gender diversity, we also examined correlation between the mean age and traditionalism, as there may be concern that age is highly correlated with traditionalism, and therefore represents an alternative explanation for our effects. The correlation was non-significant $(-.09 ; \mathrm{p}=.51)$.

${ }^{3}$ In addition, teams were formed such that there were no significant differences between conditions based on demographic composition (e.g., age, gender) within the teams.

${ }^{4}$ To provide additional validity of our idea implementing measure, we also ran a post-hoc assessment of each of the teams' ideas. Using MTurk participants, we placed each of the ideas that were generated onto a platform and asked participants to vote for the ideas that they thought would be most likely to go to market (see Dow, Fortuna, Schwartz, Altringer, Schwartz, \& Klemmer, 2012 for a similar technique). Ratings were highly correlated with our implementing feasibility measure $(r=.81, p<.05)$. 


\section{REFERENCES}

Aldrich, H., \& Ruef, M. 2006. Organizations Evolving. Sage Publications.

Amabile, T.M., Conti, R., Coon, H., Lazenby, J., \& Herron, M. 1996. Assessing the work environment for creativity. Academy of Management Journal, 39: 1154-114.

Baer, M., 2012. Putting creativity to work: The implementation of creative ideas in organizations. Academy of Management Journal, 55(5): 1102-1119.

Barry, B., \& Stewart, G. L. 1997. Composition, process, and performance in self-managed groups: The role of personality. Journal of Applied Psychology, 82 62-78.

Beckman, C. M. 2006. The influence of founding team company affiliations on firm behavior. Academy of Management Journal, 49(4): 741-758.

Behfar, K. J., Mannix, E. A., Peterson, R. S., \& Trochim, W. M. K. 2011. Conflict in small groups: The meaning and consequences of process conflict. Small Group Research, 42, 127- 146

Bezrukova, K., Thatcher, S., Jehn, K. A., \& Spell, C. S. (2012). The effects of alignments: Examining group faultlines, organizational cultures, and performance. Journal of Applied Psychology, 97(1), 77-92.

Brett, J. M., Tinsley, C. H., Shapiro, D. L., \& Okumura, T. 2007. Intervening in employee disputes: How and when will managers from China, Japan and the USA act differently?. Management and Org. Review, 3(2): 183-204.

Brinckmann, J. 2008. Competence of top management teams and success of new technologybased firms. Springer Fachmedien.

Brown, S. L., \& Eisenhardt, K. M. 1995. Product development: Past research, present findings, and future directions. Academy of Management Review, 20(2): 343-378.

Campion, M. A., Medsker, G. J., \& Higgs, A. C. 1993. Relations between work group characteristics and effectiveness: Implications for designing effective work groups. Personnel Psychology, 46(4): 823-847.

Carton, A. M., \& Cummings, J. N. 2013. The impact of subgroup type and subgroup configurational properties on work team performance. Journal of Applied Psychology, 98(5), 732-758.

Chang, P. S. 2012. A Study of Scale Construction for the Measurement of Traditionality and Modernity in the Asian American/Pacific Islander Population. (Doctoral dissertation, UGA).

Cohen, W. M., \& Levinthal, D. A. 1990. Absorptive capacity: a new perspective on learning and innovation. Administrative Science Quarterly 35: 128-152.

Cramton, C. D., \& Hinds, P. J. 2005. Subgroup dynamics in internationally distributed teams: Ethnocentrism or cross-national learning? B. M. Staw, R. M. Kramer, eds. Research in Organizational Behavior JAI Press, Greenwich, CT, 231-263.

Cronin, M. A., Bezrukova, K., Weingart, L. R., \& Tinsley, C. H. 2011. Subgroups within a team: The role of cognitive and affective integration. Journal of Organizational Behavior, 32: 831-849.

De Dreu, C.K.W., \& Weingart, L. R. 2003. Task versus relationship conflict, team performance, and team member satisfaction: A meta-analysis. Journal of Applied Psychology, 88: 741-749.

De Dreu, C.K.W., \& West, M.A. 2001. Minority dissent and team innovation: The importance of participation in decision making. Journal of Applied Psychology, 86(6): 1191-1201.

De Dreu, C. K.W. 2007. Cooperative outcome interdependence, task reflexivity, and team effectiveness: a motivated information processing perspective. Journal of Applied Psychology, 92(3), 628.

Dibble, R., \& Gibson, C.B. 2013. Collaboration for the common good: An examination of challenges and adjustment processes in multicultural collaborations. Journal of Organizational Behavior, 34: 764-790.

Dow, S. P., Fortuna, J., Schwartz, D., Altringer, B., Schwartz, D. L., \& Klemmer, S. R. 2012. Prototyping dynamics: sharing multiple designs improves exploration, group rapport, and results. In Design 
Thinking Research, Springer Berlin Heidelberg, 47-70.

Drach-Zahavy, A., \& Somech, A. 2001. Understanding teram innovation: The role of team processes and stuctures. Group Dyamics: Theory, Research and Practice, 5(2): 111-123.

Dutton, J. E., \& Ashford, S. J. 1993 Selling issues to top management. Academy of Management Review, 18 397-42.

Dutton, J. E., Ashford, S.J., O'Neill, R. M., \& Lawrence, K. A. 2001. Moves that matter: Issue selling and organizational change. Academy of Management Journal, 44(4): 716-736.

Earley, P. C., \& Gibson, C. B. 2002. Multinational work teams: A new perspective. Routledge.

Ellis, S., Mendel, R., \& Nir, M. 2006. Learning from successful and failed experience: the moderating role of kind of after-event review. Journal of Applied Psychology, 91: 669-680.

Enders, C. K. 2010. Applied Missing Data Analysis. Guilford Press.

Erez, M., \& Earley, P. C. 1993. Culture, Self-Identity, and Work. Oxford University Press: Oxford.

Farr, J. L., Sin, H. P., \& Tesluk, P. E. 2003. Knowledge Management Processes and Work Group Innovation. International Handbook of Innovation, 1171: 574-586.

Gann, D. 2000. Building innovation: complex constructs in a changing world. Thomas Telford.

Gardner, H. K., Gino, F., \& Staats, B. R. 2012. Dynamically integrating knowledge in teams:

Transforming resources into performance. Academy of Management Journal, 55(4), 9981022.

Gelfand, M. J., Erez, M., \& Aycan, Z. 2007. Cross-cultural organizational behavior. Annual Review Psychology, 58: 479-514.

Gelfand, M.J., Nishii, L. H., Holcombe, K. M., Dyer, N., Ohbuchi, K., \& Fukuno, M. 2001. Cultural influences on cognitive representations of conflict: Interpretations of conflict episodes in the United States and Japan. Journal of Applied Psychology, 86(6):1059-1074.

Gibson, C.B. 1997. Do You Hear What I Hear? A Framework for Reconciling Intercultural Communication Difficulties Arising From Cognitive Styles and Cultural Values. In M. Erez \& P.C. Earley (Eds.) New Perspectives on International Industrial/Organizational Psychology, San Francisco, CA: Jossey-Bass.

Gibson, C. B., \& Birkinshaw, J. 2004. The antecedents, consequences, and mediating role of organizational ambidexterity. Academy of Management Journal, 47(2): 209-226.

Gibson, C. B., \& Gibbs, J. L. 2006. Unpacking the concept of virtuality: The effects of geographic dispersion, electronic dependence, dynamic structure, and national diversity on team innovation. Administrative Science Quarterly, 51(3): 451-495.

Gibson, C.B. and Dibble, R. 2013. Excess may do harm: Examining the diminishing returns of external adjustment in team-based collaborations. Organization Science, 24(3): 687-715.

Gibson, C. B., Huang, L., Kirkman, B. L., \& Shapiro, D. 2014. Where global and virtual intersect: The value of examining both in $21^{\text {st }}$ century teams. Annual Review Organizational Psychology, 1(1): 217-244.

Gibson, C. B., \& McDaniel, D. M. 2010. Moving beyond conventional wisdom: Advancements in cross-cultural theories of leadership, conflict, and teams. Perspectives in Psychology Science, 5: 450-462.

Gibson, C.B., McDaniel, D., \& Szkudlarek, B. 2012. Tales from the (multicultural) field: Toward developing research conducive to proximal theory building. In Ryan, A.M.,Oswald, F.L.\& Leong, F.T.L (Eds.) Conducting Multinational Research Projects in Organizational Psychology: Challenges and Opportunities. Michigan State University.

Gibson, C. B., \& Vermeulen, F. 2003. A healthy divide: Subgroups as a stimulus for team learning behavior. Administrative Science Quarterly,48, 202-239.

Gibson, C.B., \& Zellmer-Bruhn, M. 2002. Minding your metaphors: Applying the concept of teamwork metaphors to the management of teams in multicultural contexts. Organizational Dynamics, 31(2): 101-116.

Gibson, C. B., \& Zellmer-Bruhn, M. 2001. Metaphor and meaning: An intercultural analysis of the 
concept of team-work. Administrative Science Quarterly, 46: 274-303.

Gorman, M., \& Sahlman, W. A. 1989. What do venture capitalists do?. Journal of Business Venturing, 4(4): 231-248.

Hackman, J.R., 1992. Group influences on individuals in organizations. Consulting Psychologists Press.

Hargadon, A. B., \& Bechky, B. A. 2006 "When collections of creatives become a creative collectives: A field study of problem solving at work." Organization Science, 17 484-500.

Hajro, A., Gibson, C.B., and Pudelko, M. 2016. The relationship between organizational diversity climate, knowledge exchange processes and effectiveness in multicultural teams. Academy of Management Journal.

Harrison, D. A., \& Klein, K. J. 2007. What's the difference? Diversity constructs as separation, variety, or disparity in organizations. Academy of Management Review, 32(4): 1199-1228.

Harrison, D. A., Price, K. H., \& Bell, M. P. 1998. Beyond relational demography: Time and the effects of surface-and deep-level diversity on work group cohesion. Academy of Management Journal, 41(1): 96-107.

Harrison, D. A., Price, K. H., Gavin, J. H., \& Florey, A. T. 2002. Time, teams, and task performance: Changing effects of surface-and deep-level diversity on group functioning. Academy of Management Journal, 45(5): 1029-1045.

Harrison, G.L., McKinnon, J. L., Wu, A., \& Chow, C. W. 2000. Cultural influences on adaptation to fluid workgroups and teams. Journal of International Business Studies, 31(3): 489-505.

Hayes, A.F., 2013. Introduction to mediation, moderation, and conditional process analysis: A regression-based approach. Guilford Press.

Hobsbawm, E. 1983. The Invention of Tradition. Cambridge University Press.

Hofstede, G. 1980. Culture and organizations. International Studies of Management \& Organization, 10(4), 15-41.

Hu, L.T. \& Bentler, P.M., 1999. Cutoff criteria for fit indexes in covariance structure analysis: Conventional criteria versus new alternatives. Structural equation modeling: a multidisciplinary journal, 6(1): 1-55.

Imbens, G. W., \& Lemieux, T. 2008. Regression discontinuity designs: A guide to practice. Journal of econometrics 142(2): 615-635.

Jackson, S. E., May, K.E., \& Whitney, K. 1995. Understanding the dynamics of diversity in decisionmaking teams. Decision Making in Organizations, 204: 261.

Janis, I. L. 1982. Groupthink: Psychological studies. Boston: Houghton Mitflin.

Javidan, M., \& Carl, D.E. 2005. Leadership across cultures: A study of Canadian and Taiwanese executives. Management International Review, 45(1): 23-44.

Jehn, K. A. 1995. A multimethod examination of the benefits and detriments of intragroup conflict. Administrative Science Quarterly, 40, 256-282

Jehn, K. A., \& Bendersky, C. 2003. Intragroup conflict in organizations: A contingency perspective. Research in Organizational Behavior, 25, 189-244

Jehn, K. A., \& Mannix, E. A. 2001. The dynamic nature of conflict: A longitudinal study of intragroup conflict and group performance. Academy of Management Journal, 44(2): 238-251.

Joshi, A., \& Roh, H. 2009. The role of context in work team diversity research: A meta-analytic review. Academy of Management Journal, 52(3): 599-627.

Kerr, N.L., \& Tindale, R.S. 2004. Group performance and decision making, Annual ReviewPsychology, 55: 623-655.

Kirton, M. 2006 Adaptation-innovation in the context of diversity and change. NY: Routledge.

Kirkman, B.L., Gibson, C.B., \& Kim, K. 2012. Across borders and technologies: Advancements in virtual teams research. In S.W.J. Kozlowski ed., Oxford Handbook of Industrial and Organizational Psychology, 1 789-858. New York: Oxford University Press.

Kirkman, B.L., Lowe, K.B., \& Gibson, C.B. 2017. A retrospective on Culture's Consequences: A 25year journey. Journal of International Business Studies, 48: 12-29.

Kirkman, B.L., Shapiro, D.L., Lu, S., \& McGurrin, D.P. (2016). Culture and teams. Current Opinion in 
Psychology, 8 (April): 137-142.

Klein, K. J., \& Knight, A.P. 2005. Innovation implementing: Overcoming the challenge. Current Directions in Psychology Science, 14: 243-246.

Knudsen, T., \& Levinthal, D.A. 2007. Two faces of search: Alternative generating and alternative evaluation. Organization Science, 18(1): 39-54.

Kozlowski, S. W. J., \& Bell, B. S. 2003. Work groups and teams in organizations. In W. C. Borman \& D. R. Ilgen (Eds.), Handbook of psychology: Industrial and organizational psychology, vol. 12: 333375. New York: Wiley.

Kotter International, 2013. http://www.forbes.com/sites/johnkotter/2013/08/21/googles-best-newinnovation-rules-around-20-time/

Kwan, K. 2009. Collectivistic conflict of Chinese in counseling: Conceptualization and therapeutic directions. Counseling Psychologist, 37(7): 967-986

Kwang, N. A., \& Rodrigues, D. 2002. A Big-Five personality profile of the adapter and innovator. Journal of Creative Behavior, 36: 254-268.

Lau, D., \& Murnighan, J. K. 1998. Demographic diversity and faultlines: The compositional dynamics of organizational groups. Academy of Management Review, 23, 325-340.

Leonard, D., \& Straus, S. 1997. Putting your company's whole brain to use. Harvard Business Review, 75: $110-121$.

Leung, K., Bhagat, R.S., Buchan, N.R., Erez, M., \& Gibson, C.B. 2005. Culture and international business: Recent advances and their implications for future research. Journal of International Business Studies, 36(4): 357-378.

Leung, K., Bhagat, R., Buchan, N., Erez, M., \& Gibson, C. B. 2011. Beyond national culture and culturecentricism: An integrating perspective on the role of culture in international business. Journal of International Business Studies, 42: 177-181.

Marks, M. A., Mathieu, J. E., \& Zaccaro, S. J. 2001. A temporally based framework and taxonomy of team processes. Academy of Management Review, 26(3): 356-376.

McDaniel, D. \& Gibson, C.B. 2012. Emergent Ideas in Emerging Markets: The process of discovery in organizational research. In C. L. Wang, D. Ketchen, Jr., and D. B. (Eds.), Research Methodology in Strategy and Management. Emerald Press.

Miron, E., Erez, M., \& Naveh, E. 2004. Do personal characteristics and cultural values that promote innovation, quality, and efficiency compete or complement each other. Journal of Organizational Behavior, 25(2): 175-199.

Miron-Spektor, E., Gino, F., \& Argote, L. 2011. Paradoxical frames and creative sparks: Enhancing individual creativity through conflict and integration. Organizational Behavior Human Decision Processes, 116(2): 229-240.

Mueller, J. S., Goncalo, J. A., \& Kamdar, D. 2011. Recognizing creative leadership: Can creative idea expression negatively relate to perceptions of leadership potential? Journal of Experiment. Social Psychology, 47(2): 494-498.

Niu, W., \& Sternberg, R. J. 2001. Cultural influences on artistic creativity and its evaluation. International Journal of Psychology, 36: 225-241.

Niu, W., \& Sternberg, R. J. 2003. Societal and school influences on student creativity: The case of China. Psychology in the Schools, 40: 103-114.

Paletz, S. B. F., \& Schunn, C. 2010. A social-cognitive framework of multidisciplinary team innovation. Topics in Cognitive Science, 2: 73-95.

Paulus, P. B., \& Yang, H. C. 2000. Idea Generation in Groups: A Basis for Creativity in Organizations. Organizational Behavior Human Decision Processes, 82: 76-87.

Pearce, C. L., \& Ensley, M. D. 2004. A reciprocal and longitudinal investigation of the innovation process: The central role of shared vision in product and process innovation teams (PPITs). Journal of Organizational Behavior, 25(2): 259-278.

Perry-Smith, J. E., \& Coff, R. W. 2011. In the mood for entrepreneurial creativity? How optimal group affect differs for generating and selecting ideas for new ventures. Strategic Entrepreneurship 
Journal, 5(3): 247-268.

Phillips, K. W., Mannix, E. A., Neale, M. A., \& Gruenfeld, D. H. 2004. Diverse groups and information sharing: The effects of congruent ties. Journal of Experimental Social Psychology, 40, 497-510.

Peugh, J. L., \& Enders, C. K. 2004. Missing data in educational research: A review of reporting practices and suggestions for improvement. Review of Educational Research, 74(4), 525556.

Ruef, M., Aldrich, H., \& Carter, N. 2003. The structure of founding teams: Homophily, strong ties, and isolation among US entrepreneurs. American Sociology Review, 195-222.

Rohner, R. P. 1984. Toward a conception of culture for cross-cultural psychology. Journal of CrossCultural Psychology, 15: 111-138.

Sanchez-Burks, J., Nisbett, R. E., \& Ybarra, O. 2000. Cultural styles, relational schemas and prejudice against outgroups. Journal of Personality and Social Psychology, 79: 174-89.

Sawyer, J. E., Houlette, M. A., \& Yealey, E. L. 2006. Decision performance and diversity structure: Comparing faultlines in convergent, crosscut, and racially homogeneous groups. Organizational Behaviorand Human Decision Processes, 99, 1-15.

Schwartz, S. H. (1990). Individualism-collectivism: Critique and proposed refinements. Journal of CrossCultural Psychology, 21: 139-157.

Schwartz, S. H. 1994. Are there universal aspects in the structure and contents of human values? Journal of Social Issues, 50(4): 19-45.

Shweder, R. A., \& LeVine, R. A. 1984. Culture theory: Essays on mind, self and emotion. Cambridge University Press.

Stahl, G. K., Maznevski, M.L., Voigt, A., \& Jonsen, K. 2010. Unraveling the effects of cultural diversity in teams: A meta-analysis of research in multicultural work groups. Journal of International Business Studies, 41: 690-709.

Stanko, T., \& Gibson, C.B. 2009. The role of cultural elements in virtual teams. In R.S. Bhagat \& R.M. Steers (Eds.), Handbook of Culture, Organizations, and Work, pp.272-304.Cambridge: Cambridge University Press.

Stinchcombe, A. L. 1965. Organizations and social structure. Handbook of organizations 44(2): 142-193.

Sui, Y., Wang, H., Kirkman, B. L., \& Li, N. 2015. Understanding the curvilinear relationships between LMX differentiation and team coordination and performance. Personnel Psychology.

Taggar, S.2001. Group composition, creative synergy, and group performance. Journal of Creative Behavior, 35: 261-286.

Taras, V., Kirkman, B. L., \& Steel, P. 2010. Examining the impact of Culture's Consequences: A three-decade, multi-level, meta-analytic review of Hofstede's cultural value dimensions. Journal Applied Psychology, 95: 405-439.

Taras, V., Steel, P., \& Kirkman, B. L. 2016. Does country equal culture? Beyond geography in the search for cultural boundaries. Management International Review.

Teal, E. J., \& Hofer, C. W. 2003. The determinants of new venture success: strategy, industry structure, and the founding entrepreneurial team. Journal Private Equity, 6(4): 38-51.

Thatcher, S. M. B., Jehn, K. A., \& Zanutto, E. 2003. Cracks in diversity research: The effects of faultlines on conflict and performance. GroupDecision and Negotiation, 12, 217-241.

Thomas, D. C. 1999. Cultural diversity and work group effectiveness: An experimental study. Journal of Cross-Cultural Psychology, 30(2), 242-263

Tsui, A.S., Nifadkar, S. S., \& Ou, A.Y. 2007. Cross-national, cross-cultural organizational behavior research: Advances, gaps, recommendations. Journal of Management, 33(3): 426-478.

Trompenaars, F., \& Hampden-Turner, C.H., 1998. Riding the Waves of Culture, McGraw-Hill, NY.

Turetgen, I.O., Unsal, P., \& Erdem, I. 2008. The effects of sex, gender role, and personality traits of leadership emergence: does culture make a difference? Small Group Research, 39(5): 588-615.

Tziner, A., \& Eden, D. 1985. Effects of crew composition on crew performance: Does the whole equal the sum of its parts?. Journal Applied Psychology, 70(1): 85. 
Uitdewilligen, S., Waller, M. J., \& Pitariu, A. H. 2013. Mental model updating and team adaptation. Small Group Research, 44: 127-158

Van Knippenberg, D., De Dreu, C.K., \& Homan, A.C., 2004. Work group diversity and group performance: An integrative model and research agenda. Journal of Applied Psychology, 89(6).

Van Knippenberg, D., \& Schippers, M. C. 2007. Work group diversity. Annual Review of Psychology, 58: 515-541.

Vanaelst, I., Clarysse, B., Wright, M., Lockett, A., Moray, N. \& Jegers, R. A. 2006. Entrepreneurial team development in academic spinouts: An examination of team heterogeneity. Entrepreneurship Theory and Practice, 30(2): 249-271.

Wageman, R., 2001. How leaders foster self-managing team effectiveness: Design choices versus handson coaching. Organization Science, 12(5): 559-577.

Watson, W. E., Kumar, K., \& Michaelsen, L. K. 1993. Cultural diversity's impact on interaction process and performance. Academy of Management Journal, 36: 590-602.

Weick, K.E. 1979. The social psychology of organizing: Addison-Wesley.

West, M.A. 1990. The social psychology of innovation in groups. In M.A. West \& J.L. Farr (Eds) Innovation and creativity at work: Psychological and organizational strategies (pp.309-333). London: Wiley.

West, M. A. 2002. Sparkling fountains or stagnant ponds: An integrative model of creativity and innovation implementation in work groups. Applied Psychology, 51(3): 355-387.

West, M. A., \& Anderson, N. R. 1996. Innovation in top management teams. Journal Applied Psychology, 81(6): 680.

West, M.A., \& Wallace, M. 1991. Innovation in health care teams. British Journal of Social Psychology, 21: 303-315.

Williams, K. Y., \& O'Reilly, C. A. 1998. Demography and diversity in organizations: A review of 40 years of research. Research in Organizational Behavior, 20: 77-140.

$\mathrm{Wu}, \mathrm{Y}$. 2010. Indigenous innovation for sustainable growth. In China: The next twenty years of reform and development. R. Garnaut, J. Golley, L. Song eds. Australian National University Press

Van der Kamp, M. Jehn, E., and Tjemkes, B. 2015. Faultline deactivation: Dealing with activated faultlines and conflicts in global teams. In J. L. Wildman \& R. L. Griffith (Eds.), Leading Global Teams: Translating Multidisciplinary Science to Practice (pp. 269-294). New York: Springer Science+Business.

Yang, K.S. 2003. Methodological and theoretical issues on psychological traditionality and modernity research in an Asian society. Asian Journal Social Psychology, 6 262-285.

Yi, X., Hu, W. Plucker, J. A. \& McWilliams, J. 2013. Is there a developmental slump in creativity in China? The relationship between organizational climate and creativity development in Chinese adolescents. Journal of Creative Behavior, 47(1): 22-40.

Yuki. M., Maddux, W. W. Brewer, M. B. \& Takemura, K. 2005. Cross-cultural differences in relationship- and group-based trust. Personality Sociology Psychology Bulletin, 31: 48-62.

Yukl, G. C. \& Falbe, M. 1990. Influence tactics and objectives in upward, downward, and lateral influence attempts. Journal of Applied Psychology, 75: 132-140.

Yukl, G., Kim, H. \& Chavez, C. 1999. Task importance, feasibility, and agent influence behavior as determinants of target commitment. Journal of Applied Psychology, 84(1): 137-143.

Zellmer-Bruhn, M., \& Gibson, C.B. 2014. How Does Culture Matter? A Process View of Cultural Interaction in Groups. M. Yuki, M. Brewer eds. Frontiers of Culture and Psychology series: Culture and Group Processes, 166-194. Oxford University Press.

Zellmer-Bruhn, M. E., Maloney, M. M., Bhappu, A. D., \& Salvador, R. B. 2008. When and how do differences matter? An exploration of perceived similarity in teams. Organizational Behavior Human Decision Processes 107(1): 41-59.

Zhang, Z., Zheng, X. \& Wang, L. 2003. Comparative research on individual modernity of Adolescents between town and countryside in China. Asian Journal of Sociology Psychology, 6: 61-73. 
Table 1

\section{Study 1 Descriptive Statistics and Correlations}

\begin{tabular}{|c|c|c|c|c|c|c|c|c|c|c|c|c|c|}
\hline Variable & Mean & S.D. & $\mathrm{N}$ & 1 & 2 & 3 & 4 & 5 & 6 & 7 & 8 & 9 & 10 \\
\hline 1. Age Diversity & 8.71 & 4.30 & 56 & & & & & & & & & & \\
\hline 2. Gender Diversity & .23 & .28 & 56 & -.08 & & & & & & & & & \\
\hline 3. Team Size & 4.75 & 2.46 & 56 & .11 & .02 & & & & & & & & \\
\hline 4. External Leadership & 1.52 & .41 & 56 & -.18 & .31 & .05 & & & & & & & \\
\hline 5. Collectivism & 4.15 & .40 & 56 & .17 & .04 & -.20 & -.20 & & & & & & \\
\hline 6. Power Distance & 3.84 & .38 & 56 & .04 & .01 & -.18 & -.15 & .16 & & & & & \\
\hline 7. Level of Team Traditionalism & 2.01 & 1.12 & 56 & -.11 & -.04 & $-.28^{*}$ & .01 & .21 & .19 & & & & \\
\hline 8. Diversity on Team Traditionalism & .60 & .32 & 56 & .04 & .18 & .20 & $.27^{*}$ & .02 & -.06 & $-.36^{* *}$ & & & \\
\hline 9. Team Process Conflict & 2.43 & .53 & 56 & -.17 & .10 & .03 & .38 & -.19 & -.06 & -.12 & $.24^{*}$ & & \\
\hline 10. Idea Generating & 79.74 & 10.70 & 56 & .06 & -.06 & .01 & -.04 & -.04 & $.25^{*}$ & $-.25^{*}$ & .22 & $.22^{*}$ & \\
\hline 11. Idea Implementing & 80.31 & 9.11 & 56 & .13 & -.22 & $-.28^{*}$ & $-.28^{*}$ & $.24^{*}$ & $.27^{*}$ & $.33^{* *}$ & $-.40^{* *}$ & $-.33^{* *}$ & -.08 \\
\hline
\end{tabular}

${ }^{*} \mathrm{p}<.05,{ }^{* *} \mathrm{p}<.01$ 
Table 2

Study 1 Results of Tests for Hypothesis 1-4

\begin{tabular}{|c|c|c|c|c|}
\hline \multirow[t]{2}{*}{ Predictor Variable } & \multicolumn{2}{|c|}{ Idea Generating } & \multicolumn{2}{|c|}{$\begin{array}{c}\text { Idea } \\
\text { Implementing }\end{array}$} \\
\hline & Step 1 & Step 2 & Step 1 & Step 2 \\
\hline \multicolumn{5}{|l|}{ Control Variables } \\
\hline Age Diversity & .10 & .07 & .10 & .14 \\
\hline Gender Diversity & -.06 & -.08 & -.24 & $-.20^{*}$ \\
\hline Team Size & .01 & -.09 & $-.23^{*}$ & -.12 \\
\hline External leadership & .03 & -.03 & $-.13^{*}$ & -.06 \\
\hline Collectivism & -.09 & -.11 & .13 & .16 \\
\hline Power Distance & .15 & .12 & .07 & .11 \\
\hline \multicolumn{5}{|l|}{ Main Effects } \\
\hline Level of Team Traditionalism & & $-.21^{*}$ & & $.22^{*}$ \\
\hline Diversity on Team Traditionalism & & $.19^{*}$ & & $-.25^{*}$ \\
\hline $\mathrm{F}$ & $2.16^{*}$ & $2.46^{*}$ & $2.41^{*}$ & $3.25^{* *}$ \\
\hline $\mathrm{R}^{2}$ & .16 & .25 & .13 & .25 \\
\hline$\Delta \mathrm{R}^{2}$ & & $.09^{*}$ & & $.12^{*}$ \\
\hline
\end{tabular}


Table 3

Study 2 Descriptive Statistics and Correlations

\begin{tabular}{lrrrrrr}
\hline Variable & Mean & S.D. & \multicolumn{1}{c}{$\mathrm{N}$} & 1 & 2 & 3 \\
\hline 1. Level of Team Traditionalism & 2.91 & .98 & 62 & & & \\
2. Diversity on Team & .80 & .44 & 62 & .11 & & \\
Traditionalism & 3.19 & 1.07 & 62 & $-.23^{*}$ & $.69^{* *}$ & \\
3. Idea Generating & 3.22 & 1.08 & 62 & $.62^{* *}$ & $-.24^{*}$ & $-.46^{* *}$ \\
4. Implementing Feasibility & & & & & & \\
${ }^{*} \mathrm{p}<.05,{ }^{* *} \mathrm{p}<.01$ & & & & &
\end{tabular}

Table 4

Study 2 Idea Generating and Implementing Feasibility as a Function of Level of Team Traditionalism

\begin{tabular}{lll}
\hline Measure & High Traditionalism & Low Traditionalism \\
& & \\
\hline Idea Generating & $2.93(.94)$ & $3.44(1.13)$ \\
Implementing Feasibility & $3.98(.81)$ & $2.51(.77)$ \\
\hline Note: Standard deviations are given in parentheses.
\end{tabular}

Table 5

Study 2 Idea Generating and Implementing Feasibility as a Function of Diversity on Team Traditionalism

Measure

High Diversity in Low Diversity in Team

Team Traditionalism Traditionalism

Idea Generating

$3.94(.67)$

$2.40(.81)$

Implementing Feasibility

$2.93(1.14)$

$3.53(.93)$

Note: Standard deviations are given in parentheses. 
Table 6

Study 2 Two-Way ANOVA Test of Level of Team Traditionalism and Diversity on Team Traditionalism on Idea Generating

\begin{tabular}{lccccc}
\hline Source & SS & df & MS & F & Sig \\
\hline Level of Team Traditionalism & 4.583 & 1 & 4.583 & 9.989 & .003 \\
Diversity on Team Traditionalism & 36.858 & 1 & 36.858 & 80.346 & .001 \\
Level of Team Traditionalism * & 1.686 & 1 & 1.686 & 3.675 & .040 \\
Diversity on Team Traditionalism & & & & & \\
Error & 26.607 & 58 & .459 & & \\
Total & 69.677 & 61 & & & \\
\hline
\end{tabular}

Table 7

Study 2 Two-Way ANOVA Test of Level of Team Traditionalism and Diversity on Team Traditionalism on Implementing Feasibility

\begin{tabular}{lccccc}
\hline Source & SS & df & MS & F & Sig \\
\hline Level of Team Traditionalism & 33.936 & 1 & 33.936 & 65.226 & .001 \\
Diversity on Team Traditionalism & 6.503 & 1 & 6.503 & 12.499 & .002 \\
Level of Team Traditionalism * & 1.651 & 1 & 1.651 & 3.252 & .050 \\
Diversity on Team Traditionalism & & & & & \\
Error & 30.177 & 58 & .520 & & \\
Total & 70.821 & 61 & & & \\
\hline
\end{tabular}


Figure 1

Relationship Diagram*

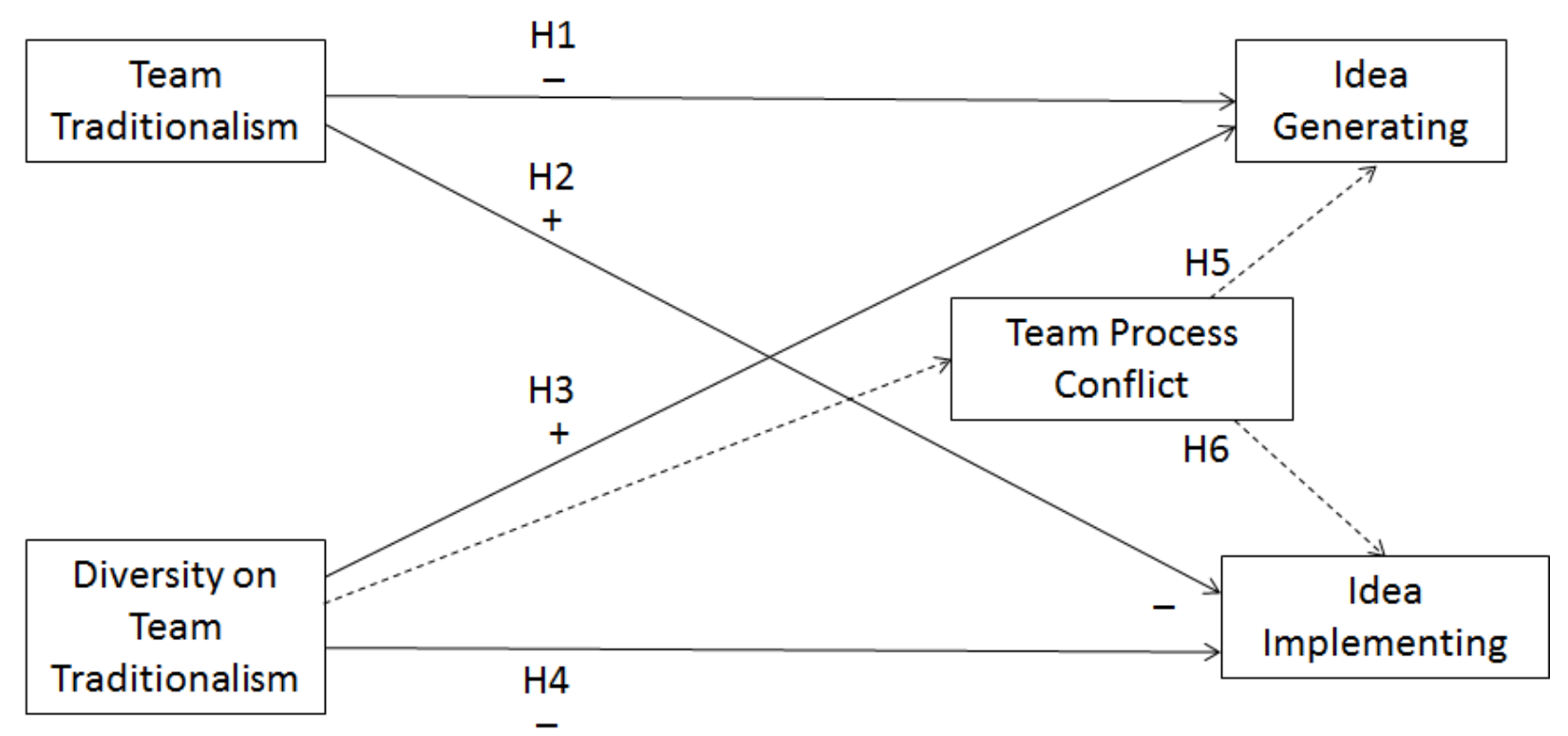

*In Study 1, idea implementing was operationalized as both and feasibility determination and application; in Study 2 only the feasibility component was included. 
Figure 2

Study 2 Ratings of Idea Generating and Implementing Feasibility

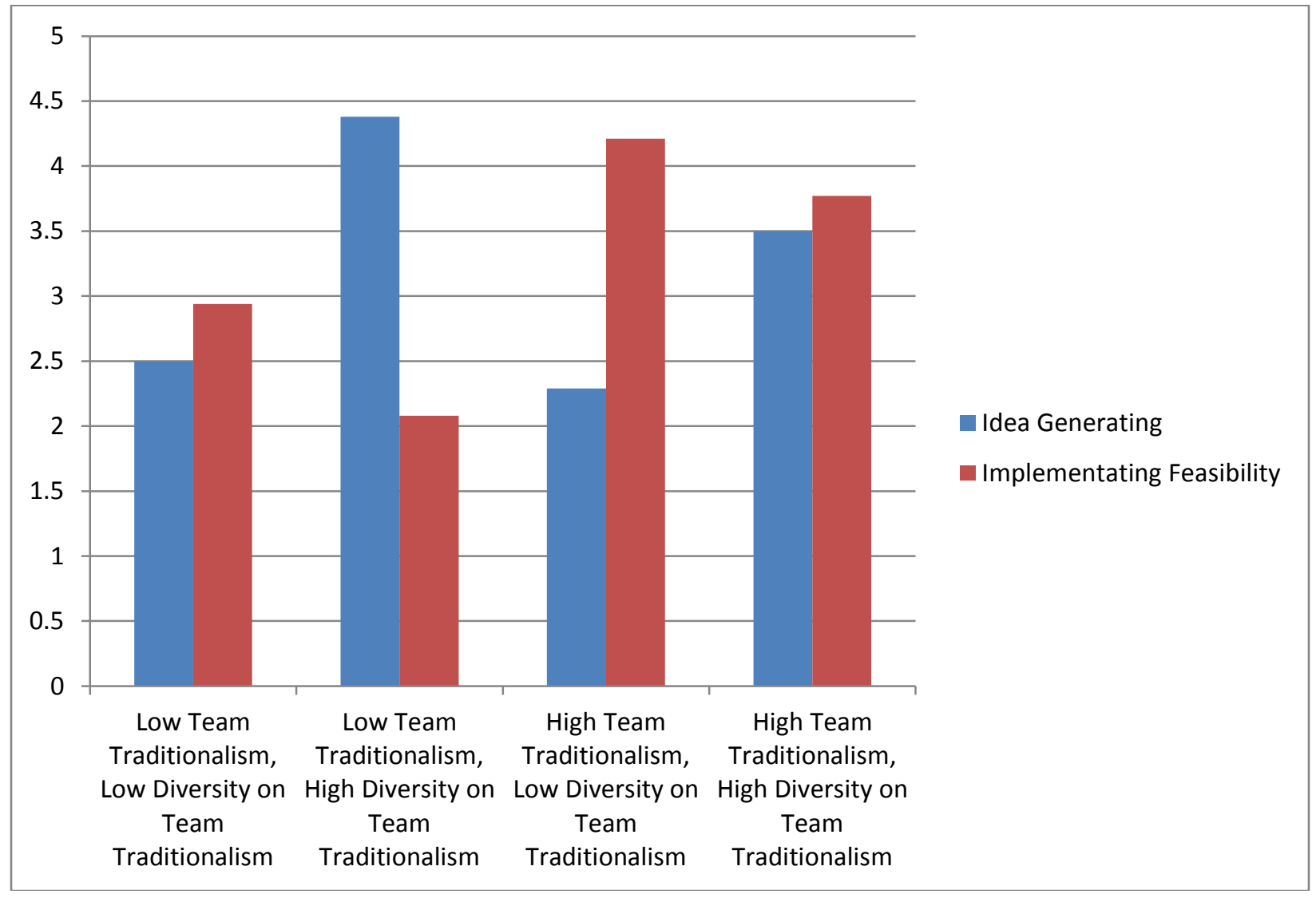

